\title{
Regulação da expressão gênica das UCP2 e UCP3 pela restrição energética, jejum e exercício físico
}

\author{
UCP2 and UCP3 genic expression: regulation by \\ food restriction, fasting and physical exercise
}

Renata Polessi BOSCHINI

Jair Rodrigues GARCIA JÚNIOR

\section{R E S U M O}

O tecido adiposo marrom, onde se localiza a proteína desacopladora 1 (UCP1 - uncoupling protein 1), é um tecido termogênico presente somente nos pequenos mamíferos e neonatos, com função de manter temperatura e peso corporal estáveis quando da exposição ao frio ou consumo de dietas hipercalóricas. Como a UCP1 está localizada exclusivamente no tecido adiposo marrom, tecido pouco expressado em adultos, os estudos dão ênfase às proteínas desacopladoras 2 e 3 (UCP2 e UCP3), proteínas homólogas à UCP1, expressas em múltiplos tecidos e nos músculos esqueléticos, respectivamente. A atividade física provoca aumento do RNAm da UCP2 e UCP3, questiona-se, porém, se este aumento é devido a mudanças no metabolismo de gordura ou a mudanças no metabolismo energético. Durante a restrição energética ou jejum, há depleção de gordura corporal e aumento da concentração plasmática de ácidos graxos livres, com regulação positiva da UCP2 e da UCP3 no músculo e aumento da oxidação lipídica. A concentração elevada de ácidos graxos representa sinal intracelular importante na indução da expressão das UCP no músculo, o que pode estar ligado à sua utilização como combustível até que ocorra aumento da demanda do organismo para dissipação da energia. No entanto, discute-se se a UCP2 e a UCP3 no músculo esquelético têm como função mediar a termogênese ou regular a oxidação de lipídios.

Termos de indexação: dieta com restrição de proteínas, expressão gênica, exercício, gordura marrom, jejum, UCP2, UCP3.

\section{A B S T R A C T}

The brown adipose tissue, where the uncoupling protein 1 (UCP1) is located, is a thermogenetic tissue only present in small mammals and neonates, with the function of keeping the temperature and body weight

\footnotetext{
1 Pró-Reitoria de Pesquisa e Pós-Graduação, Universidade Estadual do Oeste do Paraná. Rod. Raposo Tavares, km 572 , Limoeiro, 19067-175, Presidente Prudente, SP, Brasil. Correspondência para/Correspondence to: J.R GARCIA JÚNIOR. E-mail: <igjunior@unoeste.br>.
} 
stable when exposed to either cold or a hypercaloric diet. Since the UCP1 is located exclusively in brown adipose tissue, and this tissue has little expression in human adults, the studies have emphasized the UCP2 and UCP3, homologous proteins to the UCP1, expressed in multiple tissues and skeletal muscle, respectively. Physical activity increases UCP2 and UCP3 MRNA but it is now being questioned if this is due to changes in lipid metabolism or energy metabolism. During food restriction and fasting, there is a decrease in the amount of body adipose tissue and increase in the plasmatic free fatty acid concentration, with up-regulation of the UCP2 and UCP3 in the muscle, and an increase in lipid oxidation. The increase in free fatty acids represents an important intracellular indication of the induction of the UCP expression in the muscle, which can be connected to its use as fuel until there is an increased demand by the organism to dissipate energy. However the discussion continues about whether the UCP2 and UCP3 in the skeletal muscle function to mediate thermogenesis or in the regulation of lipid oxidation.

Indexing terns: diet, protein-restricted, gene expression, exercise, brown fat, fasting, UCP2, UCP3.

\section{N T R O D U Ç Ã O}

As proteínas desacopladoras (UCP) localizam-se na membrana interna da mitocôndria e têm função de translocação dos prótons e elétrons do espaço intermembranas para a matriz mitocondrial, dissipando o gradiente de prótons através da membrana interna da mitocôndria'.

No processo de síntese de trifosfato de adenosina (ATP), a cadeia respiratória transporta prótons e elétrons através da membrana interna da mitocôndria para o espaço intermembranas, criando um gradiente de prótons. No retorno dos prótons para a matriz mitocondrial, as proteínas ATP-sintases, numa reação acoplada, utilizam a energia para fosforilar o ADP (+ Pi) e sintetizar o ATP. Assim como a ATP-sintase, a UCP também está localizada na membrana interna e serve como um canal alternativo para que os prótons atravessem de volta para a matriz. Quando a UCP é estimulada, a energia não é aproveitada para a fosforilação do ADP, gerando apenas calor. A ativação desse caminho de translocação de prótons para a matriz mitocondrial resulta, indiretamente, em maior oxidação de substratos energéticos, diminuindo a eficiência da síntese de ATP e produzindo mais calor, com implicações na regulação da temperatura, do gasto energético e do peso corporal ${ }^{2,3}$. Portanto, o mecanismo de ação da UCP é desacoplar a fosforilação oxidativa da molécula de ADP4.

O tecido adiposo marrom (TAM) tem papel importante na regulação do balanço energético por ser o principal sítio de termogênese induzida pela dieta e de termogênese sem calafrios (termogênese adaptativa). Essa última tem, recentemente, despertado interesse devido ao fato de seu mecanismo ser dependente da ação das proteínas desacopladoras ${ }^{5}$.

A termogênese adaptativa promove dissipação de energia na forma de calor por estímulos externos, estando implicada no balanço energético e na regulação da temperatura corporal. Pode ser induzida pela estimulação do sistema nervoso simpático, administração de hormônios da tireóide, exposição ao frio e ingestão alimentar6-8. Num interessante estudo de Levine et al. ${ }^{6}$ com dieta hipercalórica (excesso de $1000 \mathrm{kcal} / \mathrm{dia}$ ) consumida durante oito semanas por sujeitos com peso normal, foi observada grande variação na termogênese adaptativa, que foi responsável pela dissipação de cerca de um terço do excesso de energia consumida.

O músculo esquelético é outro tecido de intensa atividade metabólica e elevado gasto energético, porém a termogênese no músculo parece não ser modulada pelo sistema nervoso simpático em resposta à dieta ou ao frio, como ocorre no TAM. Por sua vez, o tecido adiposo branco (TAB) possui baixa atividade metabólica, mas também dispõe de mecanismos moleculares relacionados à termogênese, como a atividade das UCP, principalmente quando estimulada pelo hormônio leptina $a^{9,10}$. Tais proteínas, seus mecanismos de funcionamento e regulação podem explicar a função de ambos os tecidos na homeostase energética ${ }^{7}$. 
Em 1997, duas novas isoformas da UCP (UCP2 e UCP3) foram identificadas por Fleury et al. ${ }^{11}$ e Boss et al. ${ }^{12}$, respectivamente. A UCP2 é ubiquamente expressa nos tecidos corporais e, de acordo com Ricquier \& Bouillaud ${ }^{4}$, sua função fisiológica tem relação com a regulação do metabolismo, da termogênese induzida pela dieta e controle do peso corporal.

A UCP3, expressa especificamente no tecido muscular e no TAM, está relacionada com o consumo de substratos energéticos e também com o controle do peso corporal, sendo regulada pela disponibilidade e metabolismo de substratos energéticos como lipídios e glicose ${ }^{13}$. A entrada desses substratos no músculo resulta no aumento da expressão da UCP3, levando ao aumento do gasto energético. Desde que o músculo esquelético e o TAM são considerados como importantes locais para o gasto de energia em humanos e roedores, a UCP3 pode ser um importante mediador da termogênese adaptativa ${ }^{14}$.

O processo de termogênese não é induzido somente por exposição ao frio e hibernação em algumas espécies, mas também por uma variedade de situações fisiológicas e fisiopatológicas como jejum, consumo alimentar, exercício físico, hipo e hipertireoidismo ${ }^{4}$.

Em estados de jejum, infecção e câncer, por exemplo, quando a concentração de ácidos graxos circulantes está elevada, a expressão gênica da UCP3 também aumenta comparativamente ao estado de homeostase. Essa observação encontrada num estudo de Argilés et al. ${ }^{15}$ indica que a UCP3 e, possivelmente, a UCP2, podem fazer parte de um mecanismo de proteção celular contra as conseqüências do metabolismo aumentado de substratos lipídicos e da estocagem excessiva de gordura, ou seja, a obesidade.

Estudos de Samec et al. ${ }^{16}$ e de Schrauwen et al. ${ }^{17} \mathrm{com}$ animais em jejum prolongado demonstraram aumento da expressão da UCP2 e da UCP3 em músculo esquelético. Weigle et al. ${ }^{18}$ acreditam que tal efeito esteja relacionado à maior concentração plasmática de ácidos graxos e sua utilização no metabolismo energético, já que numa situação como o jejum, o aumento da dissipação de energia pelo organismo seria um efeito paradoxal. Nosso objetivo nesta revisão é descrever e discutir as informações acerca da regulação da expressão gênica da UCP2 e UCP3 em condições de restrição energética crônica associada ao exercício físico.

\section{Localização das UCPs 2 e UCP3}

O TAM está presente em proporção significativa somente nos pequenos mamíferos e neonatos, com a função de manter a temperatura e o peso corporal estáveis quando da exposição ao frio ou consumo de dietas hipercalóricas ${ }^{19}$.

Morfologicamente e funcionalmente o TAM é distinto do tecido adiposo branco (TAB). É altamente vascularizado, contém gotículas de triacilglicerol, numerosas mitocôndrias com elevado grau de desenvolvimento da membrana interna e alta capacidade de oxidar ácidos graxos. Ao contrário, o TAB está capacitado para estocar grandes quantidades de ácidos graxos na forma de triacilglicerol. Em humanos, devido à pequena quantidade de TAM, a ativação dessa via termogênica é considerada insignificante em termos de gasto de energia ${ }^{4,20}$.

No final da década de 90 duas novas proteínas desacopladoras, UCP2 e UCP3, foram identificadas. A UCP2 apresenta 59\% de homologia dos aminoácidos com a UCP1 e é expressa em vários tecidos e órgãos, como músculo esquelético, coração, placenta, linfócitos, intestino, pulmão, fígado, rins, pâncreas e TAB ${ }^{4}$.

A UCP2 é regulada positivamente no TAB no período pós-prandial, estando envolvida com a termogênese característica desse período. Relaciona-se também com a função imune, sendo ativada durante a resposta termogênica de infecções, e é responsável pela prevenção da formação de espécies reativas de oxigênio $(E R O)^{20}$.

A UCP3 apresenta 57\% de homologia com a UCP1 e 73\% com a UCP2. É sintetizada de duas formas: longa (UCP3L) com 312 aminoácidos 
e curta (UCP3S) com 275 aminoácidos²1. É expressa seletivamente no TAM e músculo esquelético, tendo nesse último a função metabólica alterada sob condições de depleção de combustível durante o jejum e o exercício ${ }^{22}$.

Enquanto a UCP1 é conhecida pela sua função de produzir calor durante exposição ao frio, as funções da UCP2 e UCP3 não estão bem esclarecidas. Suas possíveis funções incluem: 1) controle da termogênese adaptativa em resposta à exposição ao frio e à dieta; 2) controle da produção de espécies reativas de oxigênio na mitocôndria; 3) regulação da síntese de ATP; 4) regulação da oxidação de ácidos graxos ${ }^{4,13,20,23,24}$.

Os mecanismos de regulação da oxidação de ácidos graxos, o controle da produção de espécies reativas de oxigênio na mitocôndria e a taxa de peroxidação lipídica estão diretamente relacionados entre si e com as UCP, que atuam em grau de ativação dependente da disponibilidade e fluxo de ácidos graxos no interior das células. Ricquier \& Bouillaud ${ }^{21}$ demonstraram as possibilidades de transporte de prótons para a matriz mitocondrial envolvendo a UCP e ácidos graxos. Umas delas é o transporte dos prótons apenas pela UCP, enquanto a outra é o transporte dos prótons em conjunto com ácidos graxos (na forma protonada $\mathrm{R}-\mathrm{COOH}$ ) também através da UCP, porém em maior taxa, mesmo quando da existência de baixas concentrações de ácidos graxos. Numa outra situação de elevada concentração de ácidos graxos, esses também transportariam os prótons para a matriz mitocondrial, porém nesse mecanismo o papel da UCP seria de transporte reverso da forma aniônica dos ácidos graxos (R-COO-) para fora da mitocôndria (Figura 1).

Nesse sentido, os músculos esqueléticos, com sua intensa taxa metabólica e elevada capacidade de oxidação de ácidos graxos, podem depender do papel da UCP3 no transporte dos ânions de ácidos graxos para minimizar a produção de espécies reativas de oxigênio e a peroxidação lipídica. A regulação da atividade da UCP3, portanto, se daria por meio da concentração

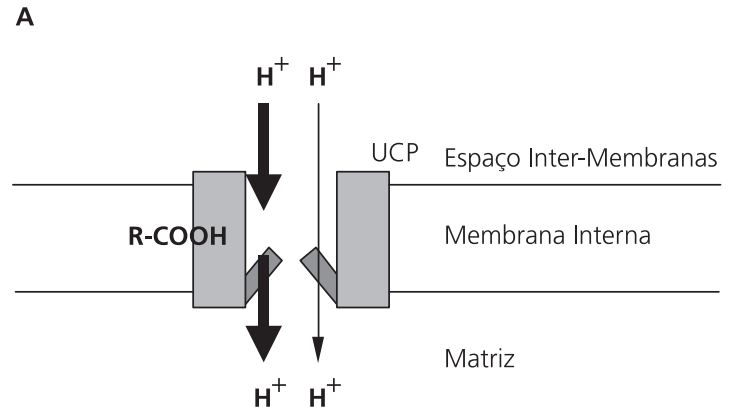

B

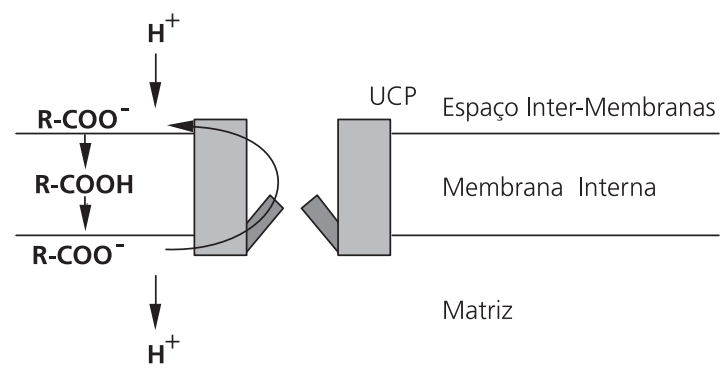

Figura 1. Representação esquemática do transporte de prótons $\left(\mathrm{H}^{+}\right)$através da proteína desacopladora (UCP) na membrana interna da mitocôndria. Devido à concentração maior de $\mathrm{H}^{+}$no espaço intermembranas há um gradiente que os move em direção à matriz. A) Os $\mathrm{H}^{+}$ podem ser transportados de forma independente como observado na seta mais fina à direita ou ligados ao grupo carboxila $(\mathrm{COOH})$ de um ácido graxo em maior taxa como mostra a seta mais espessa da esquerda. B) Em concentrações mais elevadas de ácidos graxos, a forma protonada (R- $\mathrm{COOH}$ ) pode atravessar livremente a membrana em direção à matriz, transportando os $\mathrm{H}^{+}$independentemente da UCP. O ácido graxo na forma aniônica (R-COO) retorna ao espaço intermembranas, com ajuda da UCP, completando um ciclo.

Nota: Modificado de Ricquier \& Bouillaud ${ }^{21}$.

intracelular de ácidos graxos e sua entrada nas mitocôndrias, tendo conseqüências não apenas na eficiência da ressíntese do ATP (e geração de calor) mas também na eficiência de parte dos mecanismos de defesa contra o estresse oxidativo, ao qual as células musculares estão especialmente susceptíveis durante exercícios físicos prolongados e exaustivos.

No estudo de Abu-Elheiga et al. ${ }^{25}$ foram criados animais que não expressavam a enzima acetil-CoA carboxilase, responsável pela produção 
do malonil-CoA, um substrato que controla o armazenamento e a oxidação dos ácidos graxos. Entre os resultados, destacaram-se o menor acúmulo de gordura, maior oxidação de ácidos graxos e aumento da expressão da UCP2 no tecido adiposo e da UCP3 no tecido muscular esquelético. Os próprios autores sugeriram que tal aumento das proteínas desacopladoras se caracterizou como um mecanismo para minimizar a produção de espécies reativas de oxigênio nas células que continuamente estavam oxidando ácidos graxos.

Os ácidos graxos são substratos energéticos importantes durante o jejum e o exercício físico. Um dos passos para sua utilização é a entrada na mitocôndria, num processo que depende da ligação com a carnitina, catalizado pela enzima carnitina aciltransferase I (CAT I). A administração de etomoxir, um bloqueador da CAT I, inibe a entrada e a oxidação dos ácidos graxos na mitocôndria, o que provoca a diminuição da expressão gênica do RNAm da UCP3, mesmo havendo concentrações elevadas de AGL no plasma e no meio intracelular ${ }^{26}$. Isso leva a sugerir que a expressão da UCP3 esteja relacionada com a oxidação de ácidos graxos e não apenas sua disponibilidade no citossol.

Tecidos que expressam a UCP2 e UCP3 podem atuar na regulação da oxidação lipídica, concomitantemente com a prevenção de danos oxidativos induzidos pelos lipídios ${ }^{27}$. A oxidação lipídica está diretamente relacionada à concentração de AGL no plasma, à disponibilidade de ácidos graxos no citossol e à demanda de energia principalmente pelos músculos esqueléticos. Situações como o jejum, estresse e algumas patologias provocam aumento da concentração plasmática de $A G L$, porém sem aumento significativo da demanda, como ocorre na contração muscular intensa durante o exercício físico. Nas situações de elevada concentração de ácidos graxo e baixa demanda de ATP, a ativação das UCP seria uma forma de aumentar a oxidação dos ácidos graxos disponíveis, gerando principalmente calor $^{23}$ (Figura 2). Tal mecanismo apresenta-se também vantajoso no sentido de diminuir a redução do oxigênio, processo que normalmente gera de 2 a $5 \%$ de espécies reativas de oxigênio ${ }^{28}$, os quais podem causar danos irreversíveis ao DNA da mitocôndria, membranas e proteínas intracelulares, provocando disfunção mitocondrial e posteriormente morte celular ${ }^{24}$.

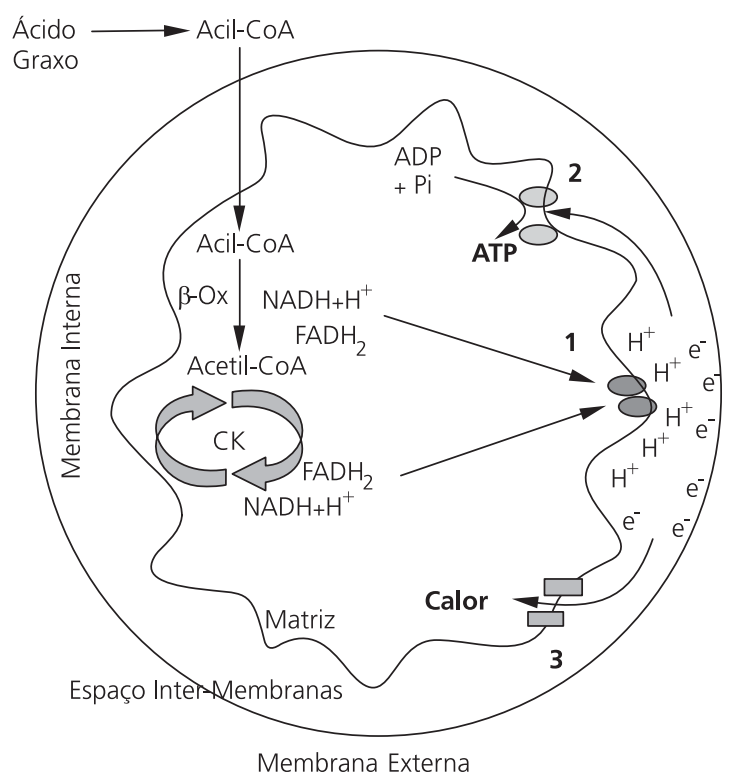

Figura 2. Representação esquemática da oxidação dos ácidos graxos e retorno dos prótons $\left(\mathrm{H}^{+}\right)$e elétrons (e-) para a matriz mitocondrial. Dentro da mitocôndria os ácidos graxos são oxidados nas reações da $\beta$-oxidação ( $\beta$-Ox) e ciclo de Krebs (CK), liberando os $\mathrm{H}^{+}$e e- que são carreados $\left(\mathrm{NADH}+\mathrm{H}^{+}\right.$e FADH $\left.{ }_{2}\right)$ até a cadeia respiratória (1). $\mathrm{O}$ gradiente de $\mathrm{H}^{+}$e e- entre o espaço intermembranas e a matriz determina seu retorno, passando pela proteína ATP sintase (2) com síntese de ATP (reação acoplada) ou pela proteína desacopladora (3) com produção de calor.

\section{Restrição energética}

Alguns estudos têm relacionado a restrição energética com a regulação das UCP2 e UCP3. O jejum prolongado e o consumo de dietas com severa restrição de energia afetam de forma diferente a expressão gênica das UCP, como demonstrado em estudos de Weigle et al. ${ }^{18}$, 
Samec et al. ${ }^{29}$ e Pedersen et al. ${ }^{30}$. Os primeiros mantiveram ratos em jejum durante 72 horas e observaram aumento da expressão gênica da UCP3 em músculos, sugerindo como causa o aumento da concentração intracelular de ácidos graxos. Situações de jejum prolongado impõem o aumento da lipólise e da concentração plasmática de AGL. Tal aumento provoca elevação da captação dos ácidos graxos e, juntamente com a disponibilidade relativamente baixa de glicose, determina a maior oxidação dos ácidos graxos, principalmente nos músculos esqueléticos e coração.

No estudo de Samec et al..$^{29}$ o tempo de jejum foi de 46 horas e, observou-se aumento de três a sete vezes na expressão do RNAm da UCP2, UCP3 e das enzimas relacionadas à oxidação dos ácidos graxos carnitina palmitoiltransferase 1 e acil-CoA desidrogenase. O dado mais interessante desse estudo é que a expressão continuou aumentada mesmo com a administração do ácido nicotínico (agente antilipolítico) e a diminuição da concentração de ácidos graxos para valores compatíveis ao estado alimentado.

Pedersen et al. ${ }^{30}$ ofereceram dieta hipocalórica restrita durante quatro semanas para mulheres obesas e, além da diminuição do peso corporal (média de 5,2kg), observaram também diminuição do gasto energético de repouso $(4,1 \%)$ e do RNAm da UCP3 (24,0\%), estabelecendo uma relação direta entre essas duas últimas variáveis. A diminuição do gasto energético de repouso é uma adaptação fisiológica comum em condições de jejum e restrição energética. A diminuição da taxa metabólica permite menor mobilização de substratos, tais como ácidos graxos dos triacilgliceróis, porque a demanda de energia é menor. De forma diferente do jejum, numa dieta hipocalórica há fornecimento de substratos exógenos, inclusive glicose, que estimulam a secreção da insulina e não permitem taxas de lipólise e oxidação dos ácidos muito intensas. A UCP3, vista sob a função de dissipação de energia e como componente ativo da termogênese adaptativa, pode também estar envolvida nas alterações para diminuição do gasto energético conseqüente da deficiência de energia na dieta ${ }^{4,22}$.

Em se confirmando a função de dissipação de energia da UCP3 de forma semelhante à UCP1 do TAM de roedores, uma informação a ser buscada será quanto a sua relevância na diminuição da taxa metabólica.

A inibição da UCP3 em condição de restrição energética, apesar de parecer lógica, não é sempre presente. Millet et al. ${ }^{3}$ estudaram indivíduos magros e obesos e mostraram correlação direta entre o índice de massa corporal (IMC) e a expressão do RNAm da UCP2. Enquanto a dieta era proporcional ou excessiva à necessidade de energia, a UCP2 permanecia aumentada, provavelmente como um mecanismo para evitar o acúmulo de gordura. Quando os indivíduos magros e obesos foram submetidos a uma restrição energética de aproximadamente 250 calorias em relação a uma dieta normocalórica, ocorreu aumento de 2 a 2,5 vezes na expressão do RNAm da UCP2 e da UCP3.

Num estudo de Simoneau et al. ${ }^{31} \mathrm{com}$ humanos, também foi observado que a expressão gênica da UCP2 no músculo esquelético é maior (1,5 vez) nos indivíduos obesos em comparação aos indivíduos magros. Por outro lado, num estudo de Oberkofler et al. ${ }^{32}$ foi observada expressão gênica do RNAm da UCP2 significativamente menor no tecido adiposo de obesos em comparação aos indivíduos magros. Nos indivíduos obesos, mesmo após a redução do peso corporal (23 $\pm 12 \mathrm{~kg}$ em um ano), a expressão gênica do RNAm da UCP2 continuou menor. Nesse grupo de indivíduos a correlação positiva entre massa de gordura e expressão da UCP2 observada no estudo de Millet et al. ${ }^{3}$ não foi confirmada, assim como parece não ter havido influência significativa da dieta sobre a expressão da proteína desacopladora.

No TAM de ratos, a expressão do RNAm da UCP2 aumenta por exposição ao frio, enquanto no músculo esquelético sua expressão é significativamente elevada com o jejum ${ }^{33}$. Lentes et al. ${ }^{34}$ acreditam que a UCP2, devido a sua ampla 
distribuição em vários tecidos, pode ter um papel muito importante na determinação da taxa de metabolismo basal (TMB). A própria leptina, que é secretada pelos adipócitos proporcionalmente ao seu volume, exerce seu papel no controle do peso corporal por ação autócrina, regulando a expressão e atividade da UCP2 presente nos adipócitos. Orci et al. ${ }^{10}$ demonstraram de forma inequívoca a ação autócrina da leptina nos adipócitos e seu efeito no metabolismo lipídico, inibindo enzimas lipogênicas e estimulando a oxidação intracelular dos ácidos graxos. Em seus experimentos, a indução da hiperlipidemia em ratos transformou os adipócitos em células especialmente aptas à oxidação de gordura, apresentando maior expressão gênica e atividade das UCP1 e UCP2.

Uma situação paradoxal tem sido observada repetidamente durante o jejum, quando há depleção de gordura corporal, aumento da concentração plasmática de $A G L$, aumento da oxidação lipídica e regulação positiva da UCP2 e da UCP3 nos músculos esqueléticos ${ }^{27}$. Em tal situação a lógica seria a diminuição da expressão de tais proteínas para permitir a diminuição da taxa metabólica basal; no entanto há aumento, que ocorre, provavelmente, para que o tecido muscular possa oxidar todo o ácido graxo à disposição.

Também uma dieta rica em gordura consumida durante quatro semanas resulta em elevada concentração plasmática de ácidos graxos, levando a mudanças no metabolismo lipídico e estimulando o aumento na expressão gênica da UCP3. Outro resultado interessante é que, em períodos mais prolongados com tal dieta, a concentração plasmática de ácidos graxos não mais se altera e a expressão gênica da UCP3 permanece estabilizada ${ }^{26}$.

Durante o jejum, a oxidação lipídica e a regulação positiva da UCP3 no músculo esquelético são aumentadas de forma mais significativa em fibras de contração rápida do que em fibras de contração lenta. É bem estabelecido que essas últimas têm predominância do metabolismo oxidativo e, portanto, são mais aptas à utilização dos ácidos graxos como combustível. Na condição de jejum, as fibras rápidas são forçadas a se adaptarem para utilizar os ácidos graxos como combustível. Tais resultados levam a sugerir que os músculos que dependem mais de glicose do que da oxidação de ácidos graxos para ressíntese de ATP, ao expressarem mais intensamente a UCP3, perdem eficiência com o treinamento físico ${ }^{16,27}$

O papel das UCP2 e UCP3 no músculo esquelético ainda não está completamente entendido e discutem-se as possibilidades de mediar a termogênese ou regular a oxidação de lipídios, principalmente quando da elevada disponibilidade e baixa demanda desse combustível ${ }^{35,36}$. De acordo com Gong et al. ${ }^{37}$, a expressão gênica das UCP2 e UCP3 no músculo esquelético é elevada durante o jejum para manter a temperatura, pois o músculo assume a função de termorregulacão do corpo.

A transição do estado alimentado para o jejum é marcada por mudanças na concentração de hormônios e de substratos energéticos. Gong et al. ${ }^{37}$, demonstraram que a regulação da expressão do RNAm da UCP3 por hormônios em dietas foi mais significativa em comparação à regulação da expressão do RNAm da UCP2, e que a concentração de UCP3 nos músculos diminuiu três vezes no hipotireoidismo e aumentou seis vezes no hipertireoidismo. Tais resultados da regulação da expressão gênica das UCP foram também confirmados por de Lange et al..$^{38}$ que demonstraram correlação positiva entre concentração da triiodotironina (T3), expressão gênica da UCP3 e taxa metabólica de repouso. Numa revisão recente de Lanni et al. ${ }^{39}$ são mostrados resultados sobre a interação do hormônio T3 com as UCP e a taxa metabólica, sendo sugerido que a estimulação da UCP pode se dar por via direta (via clássica de ativação da expressão gênica por hormônios) ou por meio de um processo metabólico integrado envolvendo principalmente a concentração de ácidos graxos, atividade da coenzima Q e produção de espécies reativas de oxigênio. 
Weigle et al. ${ }^{18}$ buscaram explicações para o paradoxo de que no jejum, condição na qual há redução do gasto energético basal, há aumento da expressão das UCP2 e UPC3 nos músculos. Eles estudaram a relação desse mecanismo com os hormônios e AGL. Os resultados confirmaram que o hipotireoidismo e o hipertireoidismo causam redução e aumento da expressão gênica da UCP3, respectivamente. Observaram também que a concentração de AGL elevava-se significativamente dentro de 24 horas de jejum, período no qual ocorre indução das UCP. Os hormônios da tireóide são reguladores do gasto energético basal e o jejum condiz com uma situação de hipotireoidismo, no entanto, a expressão da UCP3 é aumentada, levando a crer que os ácidos graxos são estimuladores tão eficientes quanto a triiodotironina.

\section{UCP2 e UCP3 e atividade física}

Em termos de homeostase energética, alguns tecidos e órgãos são particularmente importantes. O fígado e o TAB são os principais responsáveis pela conversão, armazenamento e liberação dos substratos energéticos. O músculo esquelético, por sua vez, armazena glicogênio, mas principalmente utiliza os substratos em diferentes taxas e atua como termogênico, de acordo com seu grau de atividade e de dissipação do gradiente mitocondrial de prótons, podendo elevar a taxa metabólica de repouso em $50 \%{ }^{13,23}$.

A proteína mitocondrial translocadora essencialmente termogênica, a UCP1, está localizada exclusivamente no TAM, um tecido escasso em humanos adultos; por isso, nos últimos anos os estudos vêm dando ênfase às UCP2 e UCP3, que são expressas em nosso tecido mais abundante, o músculo esquelético.

Além de sua abundância, o tecido muscular é particularmente interessante devido a sua ampla variação no grau de ativação, desde a inatividade até atividade máxima durante contração muscular intensa. Por isso, o exercício físico agudo (única sessão) e o crônico (treina- mento) podem ser moduladores da expressão gênica e atividade das UCPs ${ }^{40}$.

Boss et al. ${ }^{23}$ estudaram ratos treinados e observaram diminuição de $60 \%$ a $76 \%$ na expressão gênica da UCP3 nos músculos sóleo e tibial anterior. A contração muscular impõe maior demanda de energia na forma de ATP, por isso obriga os músculos a se adaptarem para tornar cada vez mais eficiente sua ressíntese. A UCP3, atuando como dissipadora de energia, não contribui para a eficiência da ressíntese de ATP, razão pela qual se torna lógica sua inibição com o treinamento (Figura 3).

Num estudo de Tonkonogi et al. ${ }^{41}$ foi sugerido que o treinamento físico causa mudanças na função mitocondrial no sentido de aumentar a capacidade aeróbica de ressíntese de ATP e minimizar a produção de espécies reativas de oxigênio. Adaptações da atividade das UCP, juntamente com outras que ocorrem nas demais organelas celulares e no citossol, contribuem para o aumento da taxa de metabolismo basal e de repouso.

Boss et al. ${ }^{33}$ analisaram a expressão do RNAm da UCP2 e da UCP3 no período de recuperação após oito semanas de treinamento com ratos e encontraram diminuição da expressão dessas proteínas em ambos os músculos sóleo e tibial anterior. Tal adaptação favorece o armazenamento de substratos energéticos no período de recuperação e proporciona melhor capacidade de trabalho em exercícios subseqüentes. Schrauwen \& Hesselink ${ }^{8}$ relatam estudo no qual foi observada concentração $46 \%$ menor da UCP3 em indivíduos submetidos a treinamento de endurance em comparação a sujeitos sedentários.

Em contrapartida alguns outros estudos com realização de exercício agudo são caracterizados por marcante aumento no gasto energético durante e após o exercício. Tsuboyama-Kasaoka et al. ${ }^{42}$ demonstraram em estudo com ratos que a expressão do RNAm da UCP3 foi regulada positivamente três horas após exercício de natação de uma hora, retornando ao basal 22 horas após o exercício. Consumo de oxigênio $\left(\mathrm{VO}_{2}\right)$ elevado, 

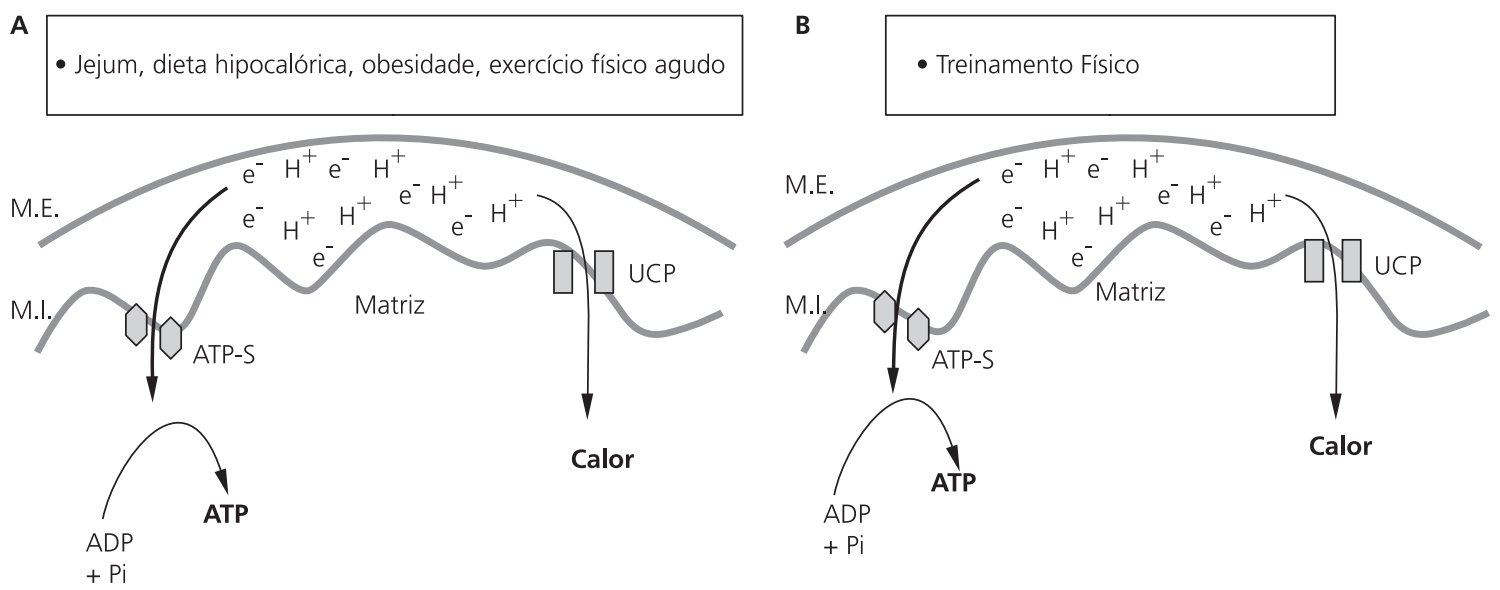

Figura 3. Representação esquemática da atividade das proteínas carreadoras da membrana mitocondrial, a ATP sintase (ATP-S) e a proteína desacopladora (UCP), em diferentes condições metabólicas. Nas setas de retorno dos $\mathrm{H}^{+}$e e- para a matriz a espessura representa a taxa de atividade das proteínas. A) nas condições listadas há aumento da concentração e oxidação dos ácidos graxos, maior expressão e atividade da UCP. B) no treinamento físico ocorrem adaptações celulares diversas para aumentar a eficiência de síntese do ATP, sendo também reduzida a expressão e atividade da UCP.

acima da taxa de repouso, é uma característica do período de recuperação, após exercício físico. Ao final do exercício ocorre uma queda brusca do $\mathrm{VO}_{2}$, seguida por uma queda lenta e depois ultralenta que pode durar horas ${ }^{43}$. O aumento da expressão e da atividade da UCP3 no período de recuperação talvez possa responder por parte desse maior $\mathrm{VO}_{2}$ e gasto energético que ocorre durante período prolongado da recuperação ${ }^{8}$.

Cortright et al. ${ }^{44}$ realizaram experimento com ratos exercitados durante uma hora em esteira e observaram que a expressão do RNAm da UCP3 estava elevada $63 \%$ em músculos vermelhos e $252 \%$ em músculos brancos, imediatamente após o esforço. Similarmente, Zhou et al. ${ }^{24}$ observaram que a expressão do RNAm da UCP3 aumentou sete vezes em músculo de ratos após 30 minutos de exercício de corrida em esteira. Além da natureza do exercício, outra característica comum desses protocolos é o aumento da concentração plasmática de AGL e da oxidação nos músculos, o que provavelmente estimulou a maior expressão da UCP3.

Em humanos, Pilegaard et al..$^{45}$ demonstraram que a expressão do RNAm da UCP3 estava aumentada quatro horas após exercício agudo.
Schrauwen et al. ${ }^{26}$, por sua vez, questionaram se o aumento de RNAm da UCP3 após exercício agudo está mais relacionado com mudanças no metabolismo de gordura ou com mudanças no metabolismo energético, conseqüência da maior demanda muscular. Num estudo, observaram que após duas horas de exercício de intensidade moderada a expressão do RNAm da UCP3 não foi afetada diretamente pelo exercício e sim pela elevada concentração plasmática de AGL, com conseqüente aumento de sua oxidação. Quando foi administrada glicose, a concentração plasmática de $A G L$ diminuiu e não ocorreu aumento significativo da expressão do RNAm da UCP3. Esse resultado é um indicativo de que a função primária da UCP3 no músculo esquelético durante o exercício não é regular o metabolismo energético, mas sim o fluxo de ácidos graxos em sua via de oxidação.

\section{CONSIDERAÇÕ ES FINAIS}

O aumento da expressão gênica e da atividade das UCP induzida pelo jejum e a sua diminuição durante o estado alimentado são fortes evidências de que a UCP2 e a UCP3 estão mais envolvidas com a disponibilidade e metabolismo 
dos AGL do que com o metabolismo energético. A elevação da concentração plasmática de AGL implica aumento de sua captação celular, entrada e utilização nas mitocôndrias, o que representa um sinal importante na indução da expressão das UCP no músculo, principalmente quando a quantidade de ácidos graxos excede a capacidade oxidativa da mitocôndria.

Portanto, as UCP parecem estar envolvidas na proteção da mitocôndria contra o acúmulo de ácidos graxos dentro da matriz mitocondrial, a produção excessiva de espécies reativas de oxigênio e a peroxidação lipídica. Essa função, dentre outras, pode preservar o equilíbrio da célula, mesmo com aumento da oxidação de ácidos graxos induzido pelo jejum. Por outro lado, a indução da expressão das UCP nos músculos pelo jejum mantém a dúvida sobre a função dessas proteínas como mediadoras da termogênese. Por isso, mais estudos são necessários para esclarecer se a UCP2 e a UCP3 têm papel na homeostase energética e na taxa metabólica quando da diminuição ou aumento do consumo de energia durante dietas hipo- ou hiper-calóricas.

\section{REFERÊ NCIAS}

1. Ricquier D, Casteilla L, Bouillaud F. Molecular studies of the uncoupling protein. FASEB J. 1991; 5(9):2237-42.

2. Harrold JA, Widdowson PS, Clapham JC, Williams G. Individual severity of obesity in unselected Wistar rats: relationship with hyperphagia. Am J Physiol Endocrinol Metab. 2000; 279(2): E340-E347.

3. Millet L, Vidal H, Andrielli F, Larrouy D, Rion JP, Ricquier $D$, et al. Increased uncoupling protein-2 and-3 mRNA expression during fasting in obese and lean humans. J Clin Invest. 1997; 100(11): 2665-70.

4. Ricquier D, Bouillaud F. Mitochondrial uncoupling proteins: from mitochondria to the regulation of energy balance. J Physiol. 2000; 529(Pt1):3-10.

5. Matamala JC, Gianotti M, Pericás J, Quevedo S, Roca P, Palou A, et al. Changes induced by fasting and dietetic obesity in thermogenic parameters of rat brown adipose tissue mitochondrial subpopulations. Biochem J. 1996; 319(Pt2): 529-34.

6. Levine JA, Eberhardt NL, Jensen MD. Role of nonexercise activity thermogenesis in resistance to fat gain in humans. Science. 1999; 283(5399): 212-4.

7. Margareto J, Marti A, Martinez JA. Changes in UCP mRNA expression levels in brown adipose tissue and skeletal muscle after feeding a high-energy diet and relationships with leptin, glucose and PPARgamma. J Nutr Biochem. 2001; 12(3):130-7.

8. Schrauwen P, Hesselink M. UCP2 and UCP3 in muscle controlling body metabolism. J Exp Biol. 2002; 205(Pt15):2275-85.

9. Ceddia RB, Willian WN, Jr Lima FB, Flandin P, Curi $R$, Giacobino JP. Leptin stimulates uncoupling protein-2 mRNA expression and Krebs cycle activity and inhibits lipid synthesis in isolated rat white adipocyte. Eur J Biochem. 2000; 267(19):5952-8.

10. Orci L, Cook WS, Ravazzola M, Purelet A, Eng WS, Di Liberto $M$, et al. Rapid transformation of white adipocytes into fat-oxidizing machines. Proc Natl Acad Sci USA. 2004; 101(7):2058-63.

11. Fleury C, Neverova M, Collins S, Raimbault S, Champigny O, Levi-Meyrueis, et al. Uncoupling protein-2: a novel gene linked to obesity and hyperinsulinemia. Nature Genet. 1997; 15(3): 269-72.

12. Boss O, Samec S, Paoloni-Giacobino A, Rossier C, Sullo A, Seydoux $V$, et al. Uncoupling protein-3: a new member of the mitochondrial carrier family with tissue-specific expression. FEBS Lett. 1997; 408(1):39-42.

13. Tsuboyama-Kasaoka N, Ezaki O. Mitochondrial uncoupling proteins 3 (UCP3) in skeletal muscle. Front Biosc. 2001; 1(6):570-4.

14. Vidal-Puig A, Solanes G, Grujic D, Flier JS, Lowell BB. UCP3: an uncoupling protein homologue expressed preferentially and abundantly in skeletal muscle and brown adipose tissue. Biochem Biophys Res Commun. 1997; 235(1):79-82.

15. Argilés JM, Busquets S, López-Soriano FJ. The role of uncoupling proteins in pathophysiological states. Biochem Biophys Res Commun. 2002; 293(4):1145-52.

16. Samec S, Seydoux J, Dullo AG. Interorgan signaling between adipose tissue metabolism and skeletal muscle uncoupling protein homologs: is there a role for circulating free fatty acids? Diabetes. 1998; 47(11):1693-8.

17. Schrauwen P, Walder K, Ravussin E. Human uncoupling proteins and obesity. Obes Res. 1999; 7(1):97-105. 
18. Weigle DS, Selfridge LE, Schwarts MW, Seeley RJ, Cumming DE, Havel PJ, et al. Elevated free fatty acids induce uncoupling protein 3 expression in muscle: a potential explanation for the effect of fasting. Diabetes. 1998; 47(2):298-302.

19. Rial E, González-Barroso MM. Physiological regulation of the transport activity in the uncoupling proteins UCP1 and UCP2. Biochim Biophys Acta. 2001; 1504(1):70-81.

20. Nordfors L, Hoffstedt J, Nyberg B, Thome A, Arner $P$, Schalling $M$, et al. Reduced gene expression of UCP2 but not UCP3 in skeletal muscle of human obese subjects. Diabetologia. 1998; 41(8): 935-9.

21. Ricquier D, Bouillaud F. The uncoupling protein homologues: UCP1, UCP2, UCP3, StUCP and AtUCP. Biochem J. 2000; 345(Pt2):161-79.

22. Hesselink MKC, Mensink M, Schrauwen P. Human uncoupling protein-3 and obesity: an update. Obes Res. 2003; 11(12):1429-43.

23. Boss $O$, Hagen $T$, Lowell BB. Uncoupling proteins 2 and 3: potential regulators of mitochondrial energy metabolism. Diabetes. 2000; 49(2): 143-56.

24. Zhou M, Lin BZ, Coughlin S, Vallega G, Pilch PF. UCP3 expression in skeletal muscle: effects of exercise, hypoxia, and AMP-activated protein kinase. Am J Physiol. 2000; 279(3):E622-E629.

25. Abu-Elheiga L, Oh W, Kordari P, Wakil SJ. Acetyl-CoA carboxylase 2 mutant mice are protected against obesity and diabetes induced by high-fat/high-carbohydrate diets. Proc Natl Acad Sci USA. 2003; 100(18):10207-12.

26. Schrauwen $P$, Hesselink MK, Vaartjes I, kornips $E$, Saris WH, Giacobino JP, et al. Effect of acute exercice on uncoupling protein 3 is a fat metabolism-mediated effect. Am J Physiol. 2001; 282(1): E11-E17.

27. Dulloo AG, Samec S, Seydoux J. Uncoupling protein 3 and fatty acid metabolism. Biochem Soc Trans. 2001; 29(Pt6):785-91.

28. Laughlin MH, Simpson T, Sexton WL, Brown OR, Smith JK, Korthuis RJ. Skeletal muscle oxidative capacity, antioxidant enzymes, and exercise training. J Appl Physiol. 1990; 68(6):2337-43.

29. Samec S, Seydoux J, Russel AP, Montani JP, Dulloo AG. Skeletal muscle heterogeneity in fasting-induced upregulation of genes encoding UCP2, UCP3, PPARgamna and key enzymes of lipid oxidation. Pflugers Arch. 2002; 445(1):80-6.

30. Pedersen SB, Borgeum JD, Kristensen K, Norrelund $H$, Otto J, Jorgensen $L$, et al. Regulation of uncoupling protein (UCP) 2 and 3 in adipose and muscle tissue by fasting and growth hormone treatment in obese humans. Int J Obes Metab Disord. 2000; 24(8):968-75.

31. Simoneau JA, Kelley DE, Neverova M, Warden $\mathrm{CH}$. Overexpression of muscle uncoupling protein 2 content in human obesity associates with reduced skeletal muscle lipid utilization. FASEB J. 1998; 12(15):1739-45.

32. Oberkofler $\mathrm{H}$, Liu YM, Esterbauer H, Hell E, Krempler F, Patsch W. Uncoupling protein-2 gene: reduced mRNA expression in intraperitoneal adipose tissue of obese human. Diabetologia. 1998; 41(8): 940-6.

33. Boss O, Samec S, Desplanches D, Mayet $\mathrm{MH}$, Seydoux J, Muzzin P, et al. Effect of endurance training on mRNA expression of uncoupling proteins 1, 2 and 3 in the rat. FASEB J. 1998; 12(3):335-9.

34. Lentes KU, Tu N, Chen $H$, Winnikes U, Reinert I, Marmann G, et al. Genomic organization and mutational analysis of the human UCP2 gene a prime candidate gene for human obesity. J Recept Signal Transduct Res. 1999; 19(1-4):229-44.

35. Noland RC, Hickner RC, Jimenez-Linan M, VidalPuig $A$, Zheng $D$, et al. Acute endurance exercise increases skeletal muscle uncoupling protein-3 gene expression in untrained but not trained humans. Metabolism. 2003; 52(2):152-8.

36. Samec S, Seydoux J, Dullo AG. Post-starvation gene expression of skeletal muscle uncoupling protein 2 and uncoupling protein 3 in response to dietary fat levels and fatty acid composition: a link with insulin resistance. Diabetes. 1999; 48(2):436-41.

37. Gong D, He Y, Karas M, Reitman M. Uncoupling protein-3 is a mediator of thermogenesis regulated by thyroid hormone, beta3-adrenergic agonists and leptin. J Biol Chem. 1997; 272(39): 24129-32.

38. de Lange $P$, Lanni A, Beneduce L, Moreno M, Lombardi A, Silvestri $E$, et al. Uncoupling protein3 is a molecular determinant for the regulation of resting metabolic rate by thyroid hormone. Endocrinology. 2001; 142(8):3414-20.

39. Lanni A, Moreno M, Lombardi A, Goglia F. Thyroid hormone and uncoupling proteins. FEBS Lett. 2003; 543(1-3):5-10.

40. Schrauwen P \& Hesselink M. Uncoupling protein 3 and physical activity: the role of uncoupling protein 3 in energy metabolism revisited. Proc Nutr Soc. 2003; 62(3):635-43.

41. Tonkonogi $M$, Krook $A$, Walsh B, Sahlin K. Endurance training increases stimulation of 
uncoupling of skeletal muscle mitochondria in humans by non-esterified fatty acids: an uncoupling-protein-mediated effect? Biochem J. 2000; 351(Pt3):805-10.

42. Tsuboyama-Kasaoka N, Tsunoda N, Maruyama K, Takahashi M, Kim H, Ikemote S, et al. Upregulation of uncoupling protein 3 (UCP3) mRNA by exercise training and down-regulation of UCP3 by denervation in skeletal muscle. Biochem Biophys Res Commun. 1998; 247(2):498-503.

43. Newsholme EA, Leech AR. Biochemistry for the medical sciences. New York: John Wiley \& Sons. 1995.
44. Cortright RN, Zheng D, Jones JP, Fluckey JD, DiCarlo SE, Grujic D, et al. Regulation of skeletal muscle UCP-2 and UCP-3 gene expression by exercise and denervation. Am J Physiol. 1999; 276(1 Pt1):E217-E221.

45. Pilegaard H, Ordway GA, Saltin B, Neufer PD. Transcriptional regulation of gene expression in human skeletal muscle during recovery from exercice. Am J Physiol Endocrinal Metab. 2000; 279(4):E806-14.

Recebido para publicação em 6 de novembro de 2003 e aceito em 12 abril de 2005. 